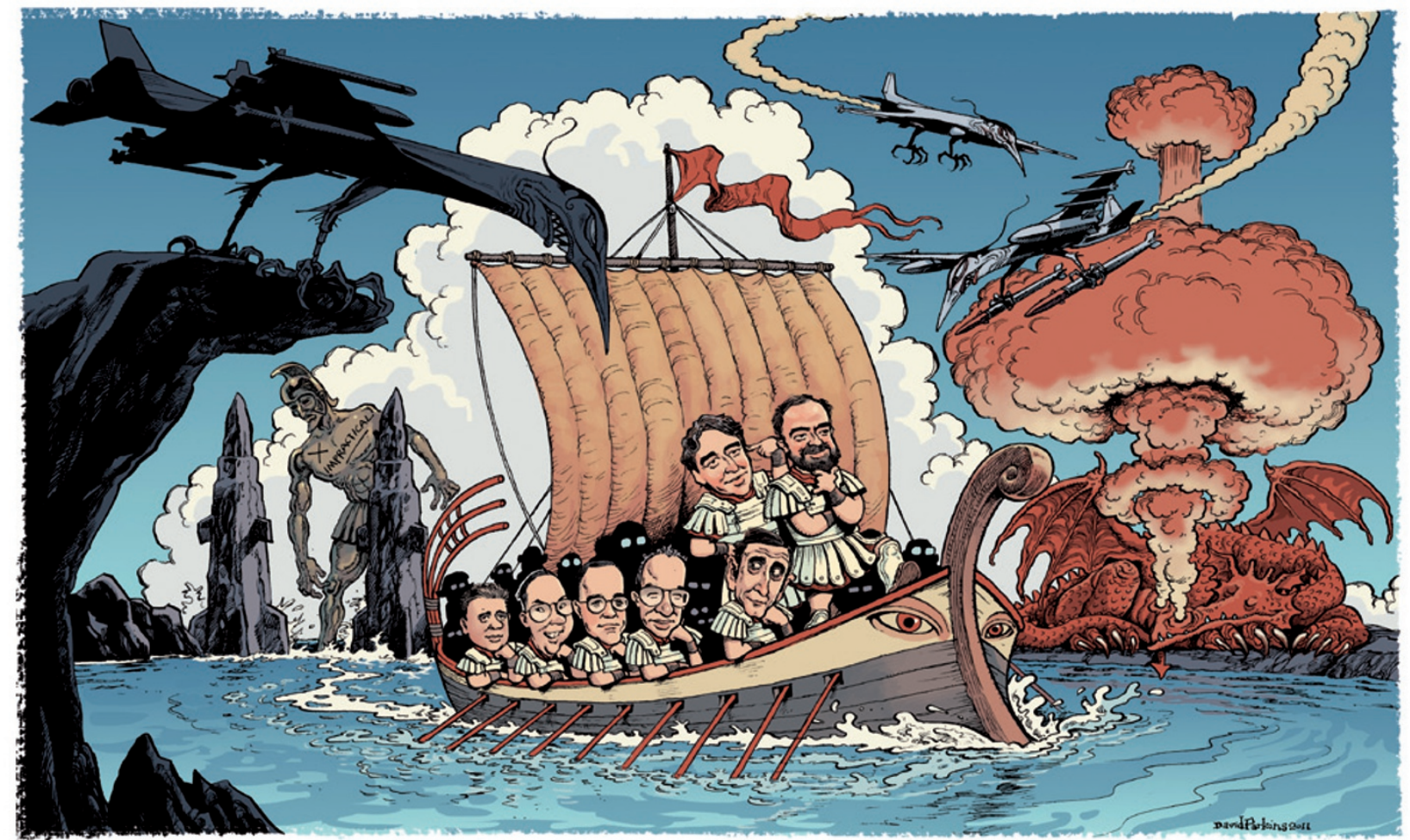

\title{
The world's most independent defence science advisers
}

\section{Ann Finkbeiner explains JASON, the autonomous group of academics that has been reporting to the US government on military matters for more than 50 years.}

$\mathrm{T}$ Ten years ago, for a short time, a 40-year-long relationship between the US Department of Defense and JASON, a small, secret group of elite science advisers, came apart. The Defense Advanced Research Projects Agency, or DARPA, directed JASON to add three specific people as members. JASON replied that it selected its own members according to exacting criteria, which the three did not meet. DARPA pointed out that it was the channel through which JASON subcontracted with others, plus the source of nearly half its budget, so JASON should accept the three, or else no channel and no money. JASON chose the latter. The relationship with DARPA was over and remains so.

JASON would have been out of business, but for the flurry of phone calls and e-mails that then went up and down the defence hierarchy. The office at the top, that of the Secretary of Defense, sent a polite note to the office of the Assistant Secretary of Defense for Research and Engineering (ASDR\&E), which sits just above DARPA: "Please look into this JASON issue and see if it makes sense to retain them." The ASDR\&E thought it did and provided JASON with a new channel and new money. As a result, JASON's position as a freelance government adviser now seems secure.

Here's the point: if you're a government and you want defence science advice that has no possible self-interest and that you can trust to be as close to the truth as nature allows, then you want an adviser that is independent enough to divorce you.

JASON is autonomous and it isn't obliged to please; its reports are technical and famously neutral. It has managed to stay in business for 50 years by maintaining a moving balance between usefulness and independence. To meet the government's evolving nationalsecurity problems, JASON adjusted its scientific expertise. And to keep the JASONs in JASON - even as members changed from theorists with summers off to scientists with labs to run - JASON remained its own boss.

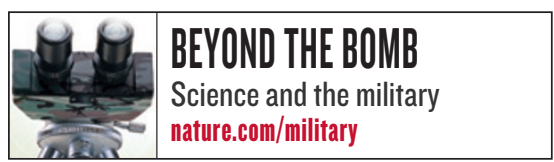

JASON comprises 30-40 scientists, mostly stellar academics, usually with broad interests, all with top-secret clearances. The scientists meet for six weeks every summer in La Jolla, California, in what they say are grubby little offices, to answer questions from five to ten sponsors, all government agencies. Questions must be well defined, specific, answerable and useful. So, as the JASONs say, no "standing around admiring the problem". And answers must be technical, that is, based on equations and arguments from scientific first principles. JASON occasionally does experiments but declines to provide examples. It doesn't touch policy.

About $40 \%$ of the questions it tackles come from a changing stable of sponsors — including the Department of Homeland Security, for which JASON has done studies on the detection of radiological material on cargo ships. The other $60 \%$ is split between the Department of Energy (on the nuclear stockpile, which JASON has so far judged to be disease-free); the ASDR\&E (on the unpredictability of rare events such as terrorist attacks, given a surprising lack of good $>$ 
data sets); and the intelligence community (we're unlikely ever to know). Half to threequarters of JASON's studies are classified. JASON currently has more requests for studies than it can accept.

Governments have many ways of getting advice from scientists, but JASON is unique. The other scientists advising the defence department are chosen by the department and often come from the defence industry. The National Academy of Sciences is selfselected and highly respected, but it prefers to work on unclassified studies, doesn't do its own research and its reports can take years. Organizations such as MITRE are science advisory corporations who work only for the government. The closest analogues to JASON in size and speed are a handful of elite groups of academics - the US Information Science and Technology group and the UK Blackett Group, for instance - that advise specific government sponsors, such as DARPA or the UK Ministry of Defence. But these sponsors created the groups, help to choose their members and the members typically rotate out after a few years.

JASON created itself: in January 1960, around 20 atomic physicists, mostly theorists, got together to advise a post-Sputnik government on nuclear matters. Researchers have always been invited to join only by JASON's self-appointed management. They stay on as active members or as senior advisers as long as they like, unless asked to quit by management. And (because everyone asks) JASON is not an acronym. It is a name given to the group by Mildred Goldberger, wife of founding member Murph Goldberger, after the Greek myth, because she thought of the advisers as golden heroes.

JASON's autonomy raises the question of how the group manages to stay in business. One reason is its members' longevity: JASON can provide its sponsors with a kind of corporate memory. Incoming head Gerald Joyce, a biochemist at the Scripps Research Institute in La Jolla, has been a member for 14 years and hasn't hit the median yet. It takes that long, he says, to "know who's on the chess board and how things are done". Otherwise, like any freelancer with a cadre of repeat customers, JASON ensures that its expertise and its customers' questions are, as JASONs say, impedance-matched - an electronics term for complementary cables that allow the fullest flow of current.

\section{NUCLEAR TO NUCLEUS}

In its first decade, JASON's studies were for DARPA and were largely related to cold-war problems of nuclear test bans and missile defence. They addressed questions such as 'could the right satellite detect the infrared signature of an enemy missile's launch?' By the early 1970s, DARPA had branched out beyond physics to materials and computer sciences. After some acrimony, JASON began adding non-physicists.

At the same time, it also began to work for other sponsors - including the Central Intelligence Agency, NASA and the new Department of Energy. For these it studied, for instance, pollution from supersonic jetliners and primitive models of climate change. Through the 1970s and early 1980s, another new sponsor, the US Navy, asked for studies on the internal ocean waves left by submarines; on the use of extremely long radio waves to communicate with submarines at great depths; and on a technique that became ocean acoustic tomography. Accordingly, by the end of the 1980 s, members included computer scientists, astronomers, geoscientists, mathematicians, materials scientists, engineers and oceanographers.

Current studies include cybersecurity, defences against improvised explosive devices and pharmaceutical intervention in cognition. Notably, several projects have been on defending against biological weapons. JASON now has what current head, Roy Schwitters, a physicist at the University of Texas at Austin, calls "a crackerjack biology crowd". In fact, in the 1990s, when JASON began to add biologists, it had to run cross-cultural training sessions, even teaching physicists to sequence DNA. Since then its studies have included: ways to counter bioweapons designers who might use genetic engineering to produce deadly microbes; possible links between the Navy's sonar exercises and mini-epidemics of beached whales; and, most recently, the potential benefits of analysing genetic
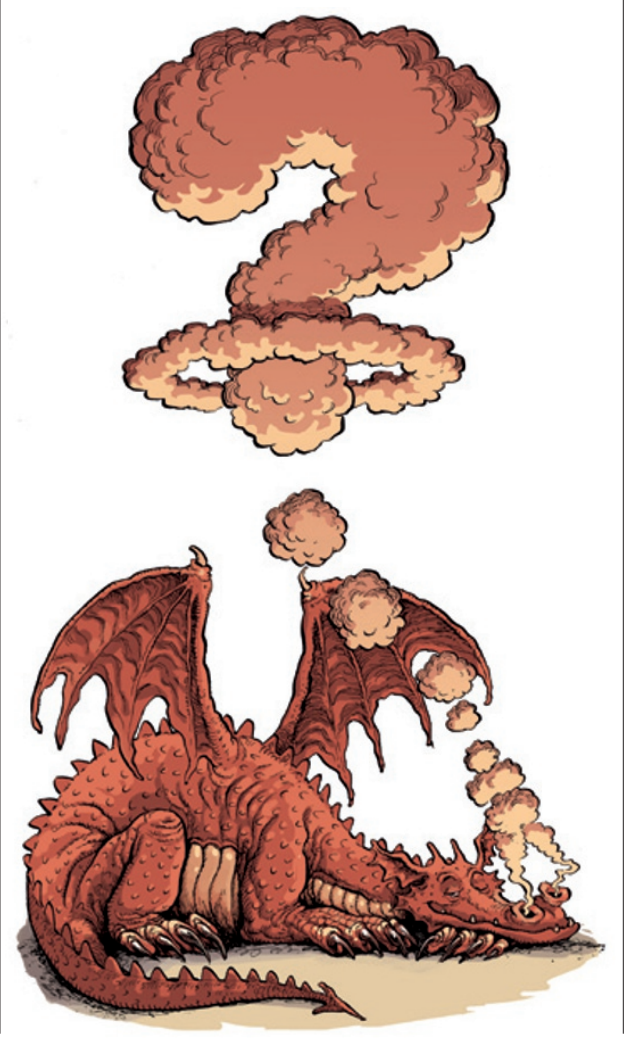

information from all military personnel. Today, only half of the JASONs are physicists.

JASON's impact is difficult to gauge. It does not formally track its studies' outcomes; most reports disappear into classified programmes or are lost in the niceties of the governmental decision-making process. The JASONs feel that their niche is advising on classified science, which cannot be sent out for peer review, is done in small, isolated communities of government scientists and, as a result, risks straying out of the realm of reality. The JASONs speculate that they've saved the government billions of dollars in non-working technologies.

Government sponsors would rather not talk about JASON's influence except in generalities. They say that the JASONs are often arrogant and naive but also scientifically smart, reliably objective and not subject to political expedience. They say they don't ask JASON unless they really want the answer, and will offer only hypothetical examples. Say the director of an agency wants to develop a technology, but it turns out not to work. He asks his agency's science advisory board for help. The board hesitates to nix the technology, so it recommends further research. The director suspects the board is being polite. He asks JASON because, as one sponsor put it, giving an unworkable technology to JASON is like throwing raw meat to a lion.

Here's a real case: on JASON's advice, the ASDR\&E killed a programme to develop a rail gun for the army. JASON had found that a gun powered by an electric current could shoot projectiles along a pair of metal rails farther and faster than conventional artillery, but making it small enough to put on a tank would require too many miracles.

\section{A VISIBLE IMPACT}

The exception to the general opacity about JASON's impact is a series of studies the group has been doing since its birth on the technologies underlying nuclear test bans. The first JASONs - who were, or were trained by, scientists involved in the Manhattan Project - inherited a need to control nuclear weapons. Early on, JASON worked on various ways to verify whether a country was cheating on a nuclear treaty by testing weapons. For instance, could you tell the difference between the seismic signature of a nuclear test and that of an earthquake? Would a test in an underground cave muffle the explosion's seismic signature? Later, JASON worked on ways to find out whether the nuclear stockpile had become old and ineffectual, and therefore an unreliable deterrent. In 1995, a JASON study ruled that nuclear weapons could be judged reliable without being tested, allowing the administration of President Bill Clinton to sign the Comprehensive Test Ban Treaty.

Current studies, done for the Department of Energy, continue to focus on the nuclear 
stockpile. JASON now sees a healthy stockpile as obviating the need for designing new weapons and as an alternative to resuming underground testing. One such study helped to doom the push, by the administration of former president George W. Bush, to develop a new bomb: the Reliable Replacement Warhead. Over the years, JASON's studies have vetted the national laboratories' nuclear stockpile programmes enough times that Congress occasionally mandates that a programme can't be re-funded until JASON reviews it.

The JASONs feel strongly about this work. Scientists' role in maintaining public confidence in the nuclear deterrent, says Schwitters, is "incredibly important". Joyce agrees: "We feel responsible to the heritage."

Today, the group's biggest challenge is keeping the JASONs attending regularly - they call it the 'sticking coefficient'. The JASONs are paid a large amount US $\$ 850$ per day in 2004 — although they could make ten times more consulting for industry. They also admire each other and take pleasure in working together on topics new to all of them; they say it is like being in graduate school again. And their interest in the country's security is intense.

But working for six weeks of an academic's precious summer, summer after summer, carries costs to his (just $10 \%$ of the JASONs are women) research, career and family life. So some JASONs come to La Jolla for just four days a week, or come one summer and not the next, or show up only for certain studies. Nobody likes that: too much of JASON's value to both its sponsors and its members depends on long, argumentative interactions. "It can't be done casually," says one member.

When Joyce becomes head in the autumn, he will survey JASON's expertises - which he thinks of as finding keywords for each member - and ask regular sponsors which keywords they need most. He will tell the sponsors that the JASONs don't think they can usefully do socialscience studies (occasionally requested for understanding insurgents and terrorists) and remind them that JASON doesn't advise on policy.

"We work with the sponsor to find the right study," he says. "We operate on billable hours, and our budget is the sum of what we're doing. We're sort of a collective independent contractor. There are others out there, but this model is very powerful." -

Ann Finkbeiner is the author of The Jasons: The Secret History of Science's Postwar Elite and was a columnist for Defense Technology International. e-mail:anniekf@gmail.com

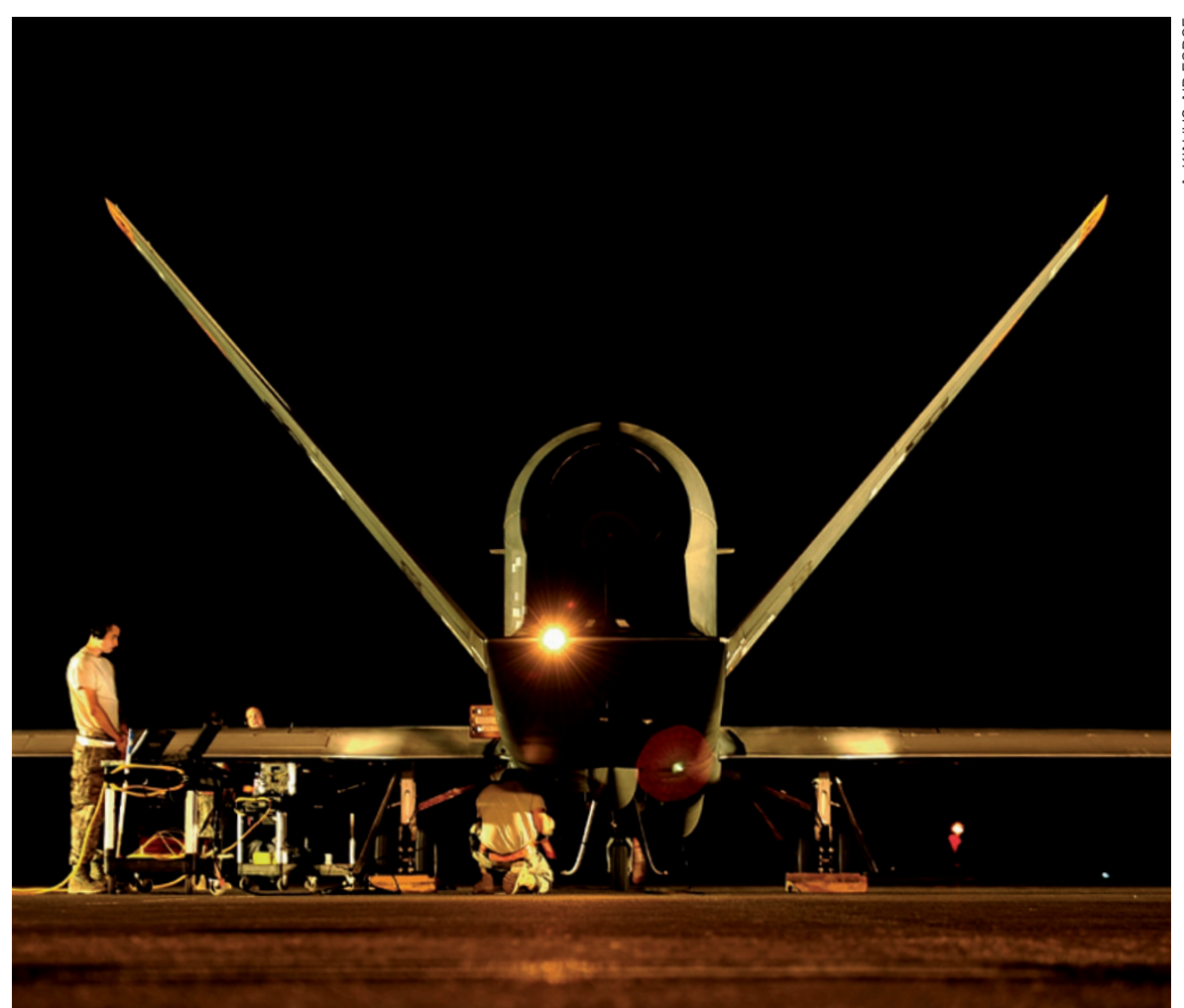

An RQ-4 Global Hawk unmanned aerial vehicle before a mission in southwest Asia in November 2010.

\section{A world of killer apps}

\section{Leaders are ill-prepared for the ethical complications of new 'killer applications', says P. W. Singer.}

A president arguing that his nation isn't at war because his forces are using only robotic weapons. An armscontrol meeting forlornly trying to ban the development of armed autonomous robots. Criminals using tiny robotic helicopters in a jewellery heist. These are not tales from an Isaac Asimov novel; they are real events that happened within the past year.

From gunpowder to the atomic bomb to robots, history is full of weapons technologies so disruptive that they change the rules. These deadly applications, or 'killer apps', often begin in the military sector but have ripple effects beyond their intended uses. The Manhattan Project to develop the first atomic bomb was at its core a militaryfunded experiment to bundle the greatest explosive power into the smallest delivery package possible.

But that research opened up entirely new areas of physics, revolutionized the energy

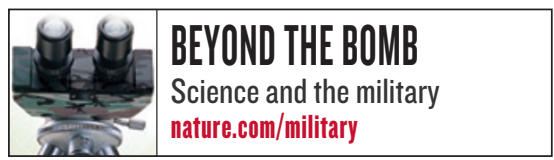

industry and transformed world politics.

What is different today is the speed with which our technology can outpace our ethical and policy responses to it. Astounding advances grab the headlines so frequently that the public has become numb to their significance - whether it is robotic planes, directed-energy weapons such as highenergy lasers, or 'electric skin', tiny sensors that are applied to the body like tattoos.

We are "giants" when it comes to technology, but "ethical infants" when it comes to understanding its consequences, as US Army general Omar Bradley remarked in 1948. Bradley was referring to nuclear research, but as the pace of technologic change takes off, that gulf - between our sophisticated inventions and our crude grasp of the consequences - continues to widen. We need to start bridging it.

\section{I, ROBOT}

Robotics is an excellent case study of this gulf. Over the past ten years, the United States and 45 other nations have gone from looking at robots as mere science fiction to using them in their military forces. For 